\title{
How We do It. Trimalleolar Fractures: Fixing the Posterior Malleolus by Posterolateral Approach
}

\footnotetext{
${ }^{1}$ Mandeep S Dhillon, ${ }^{2}$ Kamal Dureja, ${ }^{3}$ Sandeep Patel, ${ }^{4}$ Tungish Bansal
}

\begin{abstract}
The understanding of trimalleolar fractures and, in particular, the posterior malleolus fragment has drastically evolved over the last decade. There has been a tilt in favor of fixing almost all posterior malleolus fragment in contrast to the old school thought of the 20th century. The concept of stability offered by posterior malleolus fixation to the syndesmotic stability is well understood now. Posterolateral approach has almost evolved as a gold standard approach for posterior malleolus fixation.
\end{abstract}

Keywords: Ankle fracture, Posterior malleolus, Posterolateral approach ankle.

How to cite this article: Dhillon MS, Dureja K, Patel S, Bansal T. How We do It. Trimalleolar Fractures: Fixing the Posterior Malleolus by Posterolateral Approach. J Foot Ankle Surg (AsiaPacific) 2017;4(2):63-68.

\section{Source of support: Nil}

Conflict of interest: None

\section{INTRODUCTION}

In the modern era, trimalleolar fractures are more commonly seen, and have been estimated to constitute 7 to $14 \%$ of all ankle fractures. ${ }^{1,2}$ Isolated posterior malleolus fractures are rare, constituting only 0.5 to $1 \%$ of the total. The presence of posterior malleolus fracture is a poor prognostic factor compared with other ankle fractures. ${ }^{3}$ The management of posterior malleolus fractures has been a subject of debate for a long time now. Previously, the size of the fragment (as seen on lateral radiograph) was taken as the sole criteria to decide whether fixation was needed. One-fourth to one-third involvement of the articular surface and a displacement of more than $2 \mathrm{~mm}$ were defined as criteria for fixation. ${ }^{4-6}$ In recent years, there has been a paradigm shift from this thought

\footnotetext{
${ }^{1}$ Professor and Head, ${ }^{2}$ Surgeon, ${ }^{3}$ Assistant Professor, ${ }^{4}$ Junior Resident

1,3,4 Department of Orthopaedics, Postgraduate Institute of Medical Education and Research, Chandigarh, India

${ }^{2}$ Department of Orthopaedics, Max Super Speciality Hospital New Delhi, India

Corresponding Author: Sandeep Patel, Assistant Professor Department of Orthopaedics, Postgraduate Institute of Medical Education and Research, Chandigarh, India, Phone: +919901440404, e-mail: sandeepdrpatelortho@gmail.com
}

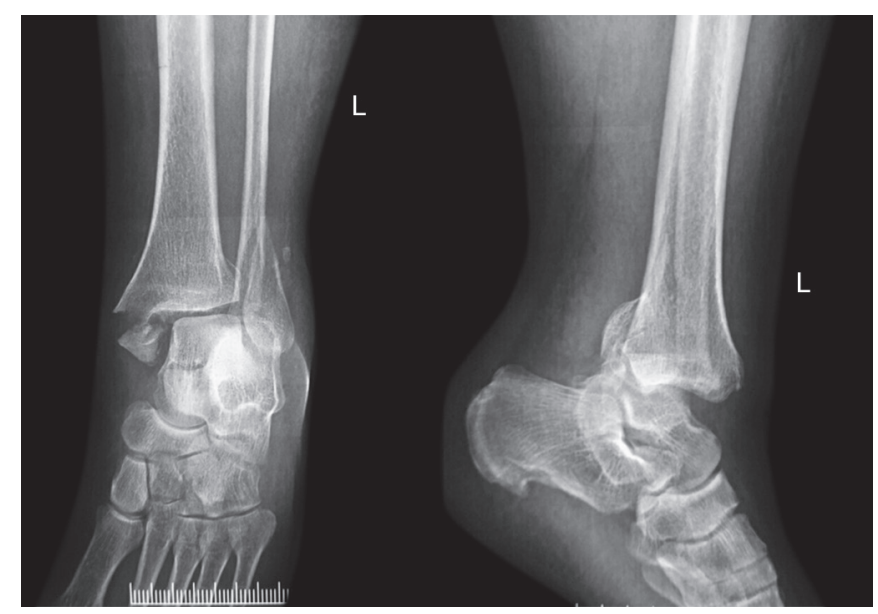

Fig. 1: The AP and lateral view of a trimalleolar fracture

process. The importance of posterior syndesmosis stability and fibular notch congruence has been highlighted. ${ }^{7,8}$ The posterolateral approach has emerged as a viable option for fixation of posterior malleolus. ${ }^{9,10}$

In this article, we discuss the operative technique for fixation of posterior malleolus through posterolateral approach.

Utility: For internal fixation of the posterior malleolus (Fig. 1, X-ray).

Ideal: For internal fixation of distal fractures of fibula within $5 \mathrm{~cm}$ from tip of lateral malleolus.

\section{PREOPERATIVE PLANNING}

At the initial presentation, the patients are assessed for local skin condition and distal neurovascular status. Special note is made of any swelling, edema, blisters, or poor skin condition. Standard anteroposterior (AP), lateral, and mortise views of the ankle are obtained. The injuries to medial, lateral, and posterior malleolus are defined and any frank dislocation or subtle subluxation identified. A possible mechanism of injury based on Lauge-Hansen classification ${ }^{11}$ is identified, as this gives an idea of injury severity and fracture distracting forces. If the skin condition is poor or swelling present, we proceed with application of ankle spanning external fixator (Fig. 2) and wait for the skin condition to improve. Computed tomography (CT) scan of the affected ankle is obtained in all cases (postspanning if external fixator is applied). Standard axial, coronal, and sagittal cuts are obtained (Fig. 3); the axial and sagittal cuts are of most 


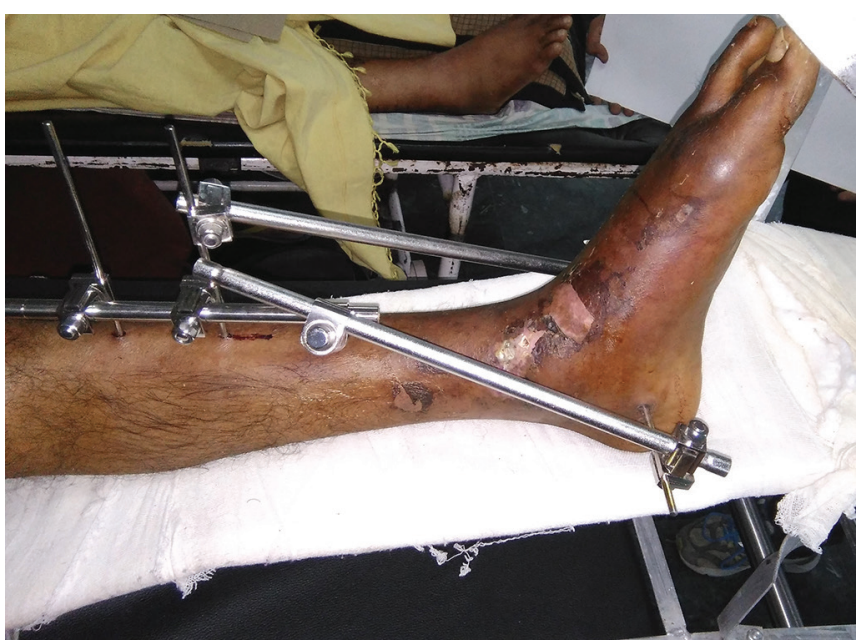

Fig. 2: An ankle fracture with swelling, blisters managed initially with transarticular fixator and elevation on Bohler-Braun splint

value. The size of the fragment of posterior malleolus, comminution, and status of the syndesmosis is looked at and noted. The size of the posterior fragment is calculated as percentage area of the total tibial plafond in axial and sagittal cuts. We follow and classify the posterior malleolus as per Bartoníček et al. ${ }^{12}$

\section{Three-dimensional CT Classification}

Once the skin condition improves and wrinkle sign appears, we proceed with fixation of the fractures. We fix all fractures of the posterior malleolus irrespective of the size of the fragment by open reduction and internal fixation by posterolateral approach to the ankle.

Patient position: Prone position (Fig. 4) is preferred, though in exceptional situations semiprone to lateral position is acceptable.

The patients are generally operated under general anesthesia in prone position laid on bolsters. The foot

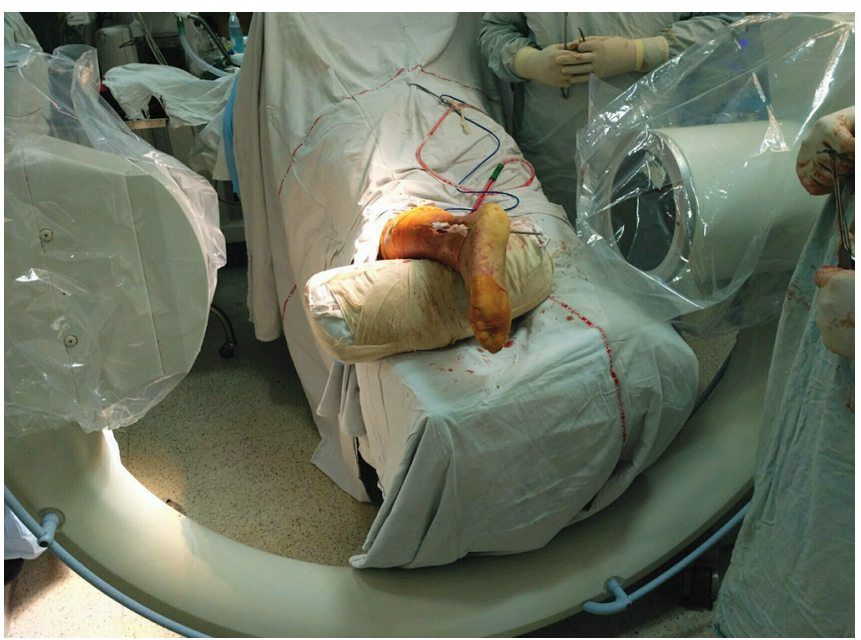

Fig. 4: Prone position of patient, with a sterile bolster underneath the leg
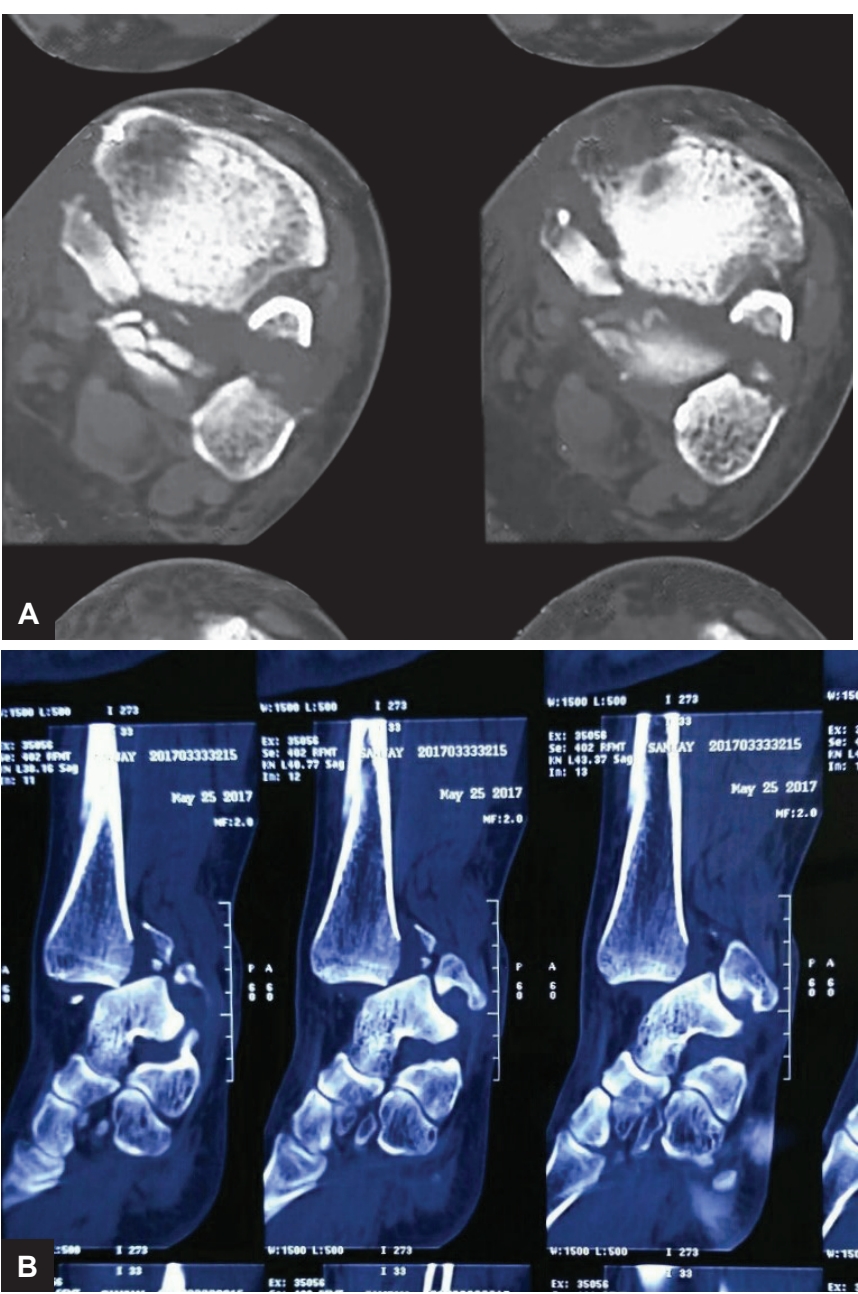

Figs $3 A$ and $B$ : The CT scan images: axial cuts (A) and sagittal cuts $(B)$ help in defining the fracture pattern of posterior malleolus

and ankle overhangs the distal edge of table. The knee is slightly flexed and a sterile bolster is placed underneath the legs in such a way that ankle dorsiflexion is not hindered. Proper unhindered AP and lateral views of ankle are confirmed with C-arm before draping. A tourniquet is applied. Posterior superior iliac crest is painted and draped in cases where we anticipate the need for bone graft.

\section{ANATOMICAL LANDMARKS}

Lateral malleolus is traced along posterior border proximally for 4 to $5 \mathrm{~cm}$.

Lateral border of tendo achilles. These landmarks are marked as shown in Figure 5.

The incision is marked midway between lateral border of tendo achilles and posterior border of fibula.

\section{Variations}

- If only posterior malleolus is to be dealt and CT shows a major part of it medial to midline, incision can be placed closer to lateral border of tendo achilles. 


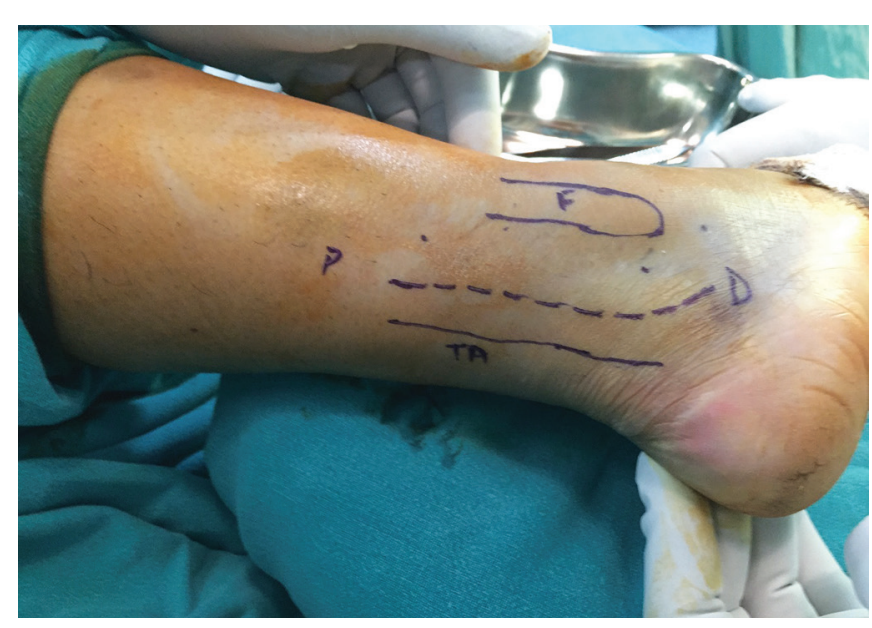

Fig. 5: Skin markings of anatomical landmarks before Incision. TA: Tendo Achilles lateral border, F: Fibula distal part, Dotted Line: Incision line, P: Proximal end, D: Distal extent

- If lateral malleolus fixation is to be dealt, a slight curve toward tip of lateral malleolus distally is helpful

\section{Extension}

Though incision can be extended proximally, bulk of deep muscles of posterior compartment do not offer exposure of more than 5 to $6 \mathrm{~cm}$ of distal posterior tibia comfortably.

\section{Dissection}

The skin is incised superficially and subcutaneous plane is dissected by blunt dissection. Short saphanous vein and sural nerve cross the incision in proximal half from medial to lateral side. Both the structures are dissected in a way to be taken along with lateral skinfold to avoid injuring sural nerve.

Deep fascia is divided in line of skin incision.

Deep dissection is internervous plane created between flexor hallucis muscle on medial side (supplied by posterior tibial nerve) and peroneus longus (supplied by deep peroneal nerve) (Fig. 6A).

Sharp dissection is required to elevate flexor hallucis longus (FHL) from its origin from posterior border of distal fibula. The posterior surface of distal tibia is exposed and the posterior malleolar fragment carefully mobilized. Great care must be taken to preserve the posterior inferior tibiofibular ligament.

Loose osteochondral fragments and debris in the joint are removed and the fragment is reduced in an anatomical fashion. The reduction is provisionally fixed with Kirschner wires and checked under image intensifier and under direct vision (Fig. 7). Definite fixation is done by buttress plating preferably using a one-third tubular plate. However, a small fragment can be dealt with two small $2.7 \mathrm{~mm}$ or $3.5 \mathrm{~mm}$ lag screws passed in posteroanterior direction. The direction of compression screw through the posterior malleolus is posterior to anterior with ankle in $15^{\circ}$ internal rotation (this avoids malposition of screw into distal tibiofibular joint).

Sequence of fixation (in a trimalleolar fracture):

- First, posterolateral approach (plane between peronei and FHL) and fixation of posterior malleolus

- Second, posterolateral approach (plane lateral to peronei tendons) and fixation of distal fibula

- Third, fixation of medial malleolus

Note that fixation of fibula is done after posterior malleolus because the plate used to fix distal fibula lies directly over the posterior malleolus fracture line on lateral radiograph and hence hinders in judging the reduction of posterior malleolus.

Next, the associated lateral malleolus fracture is addressed by the same approach but through a window. Dissection is carried out lateral to peroneus tendon and fracture site is exposed and fracture reduced (Fig. 6B). The fixation is done with lag screws and neutralization
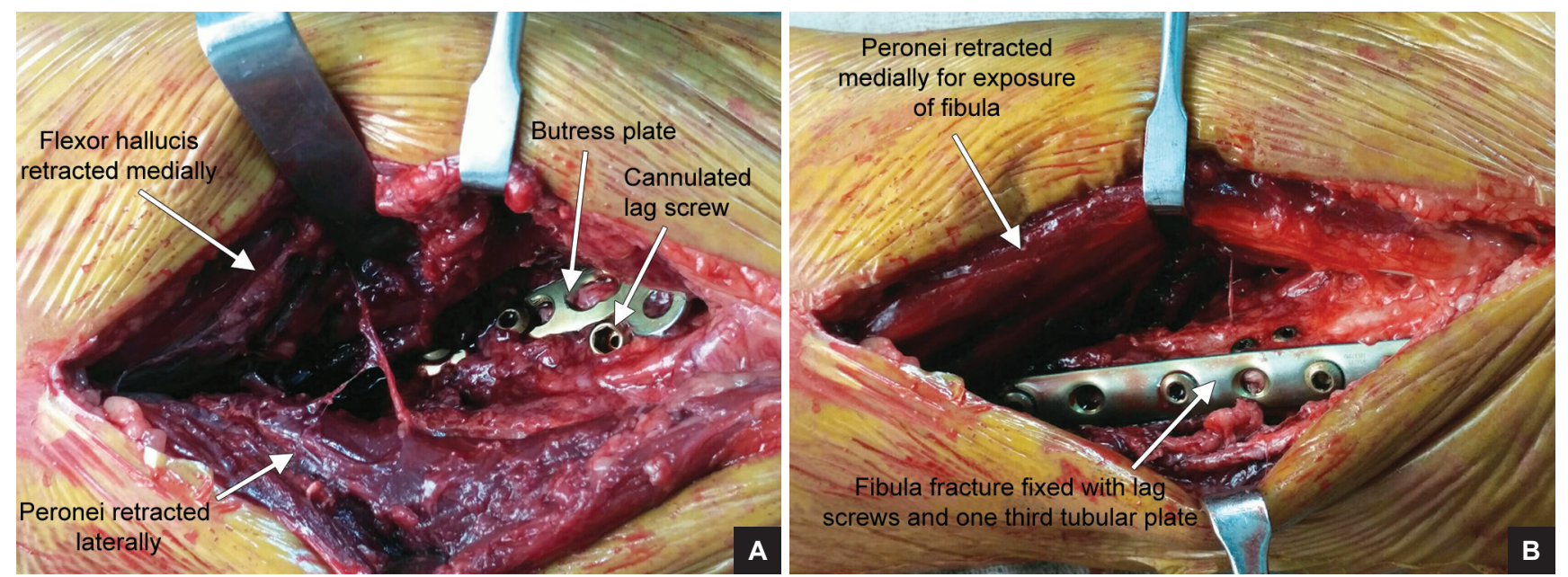

Figs 6A and B: (A) Exposure and fixation of posterior malleolus (cannulated lag screw to achieve compression and buttress plate for buttressing the comminuted fragments); (B) exposure and fixation of fibula 


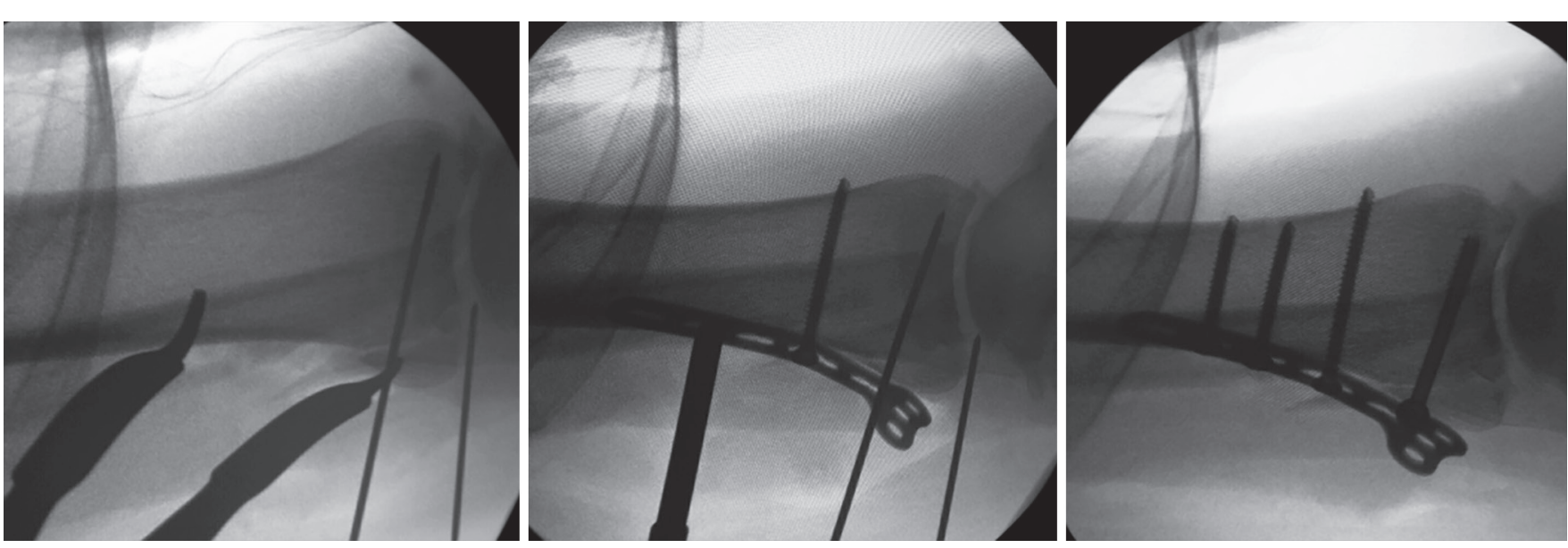

Fig. 7: Sequential intraoperative $\mathrm{C}$ arm pictures depicting reduction and fixation of posterior malleolus with cannulated screw and buttress plate

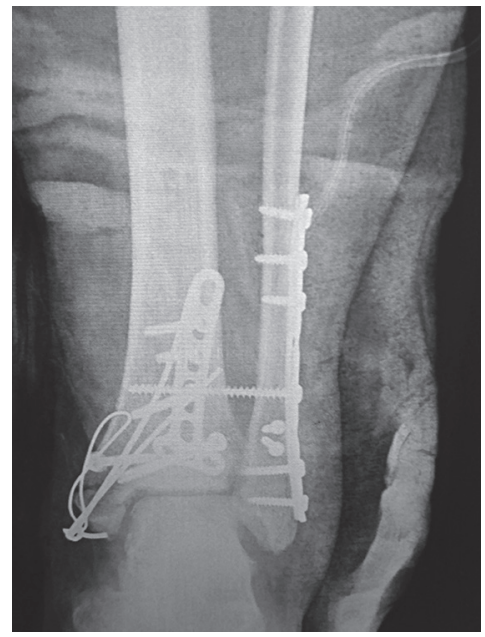

Fig. 8: Postoperative AP view, note the syndesmotic screw put in addition to fixing posterior malleolus to stabilize the syndesmosis

plate. Most surgeons place a syndesmotic screw where possible (Fig. 8), as the addition of a syndesmostic screw also stabilizes the syndesmosis and offloads distractive forces on the posterior malleolus through the posterior tibiofibular ligament (PTFL). The syndesmotic reduction is checked under direct vision and with the help of image intensifier. This has been disputed by some authors ${ }^{8}$ who feel that stabilizing the PTFL through rigid fixation of the posterior malleolus may do away with the need for syndesmosis screws.

The medial malleolus fractures are addressed lastly. In the prone position, exposure to medial malleolus is permitted by decreasing the height of the table to the minimum and an assistant holding the leg with the knee in flexion of $90^{\circ}$ (Fig. 9). The medial malleolus is now accessed via the standard medial approach and is fixed with two malleolar screws or partially threaded canulated screws or tension band wiring as per the fracture pattern.

Wound closure is done in layers, deep fascia with 2-0 Vicryl followed by subcutaneous layer with 2-0 Vicryl.

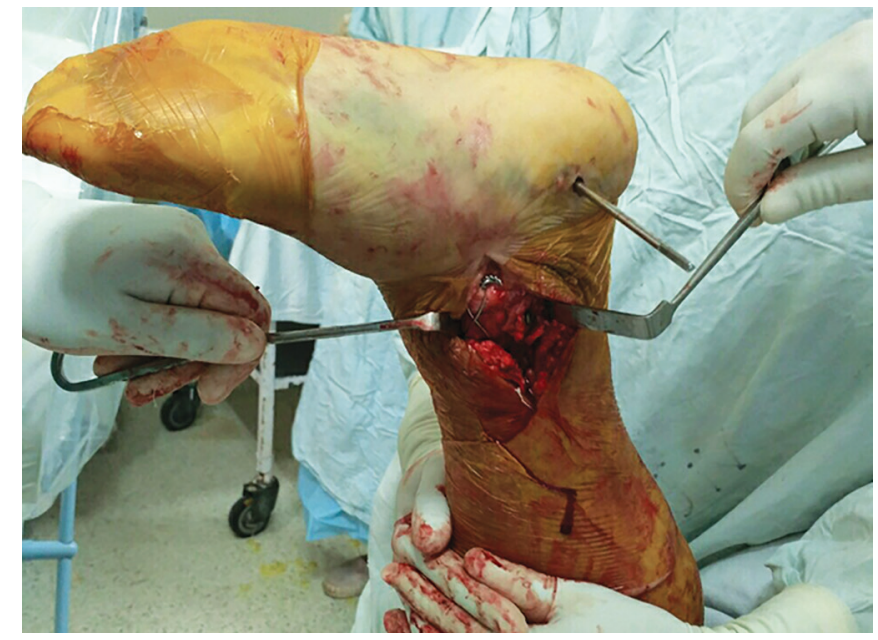

Fig. 9: Position of leg and ankle for exposure of medial malleolus. Note the assistant holding the leg with the knee in flexion of $90^{\circ}$

Interrupted skin sutures with 3-0 Nylon or Staples are then given (Fig. 10).

\section{POSTOPERATIVE MANAGEMENT AND REHABILITATION PROTOCOL}

Limb elevation is continued to decrease postoperative swelling. We generally apply a below-knee slab for 1 week with the ankle in neutral position to decrease postoperative pain and better soft tissue healing. Ankle range of motion is encouraged and started as soon as possible. Weight bearing is delayed for 6 to 8 weeks until the fracture consolidates and radiological signs of healing can be seen. The patient is mobilized with crutches with no weight bearing on affected limb. We can also use ankle offloading ankle foot orthosis (e.g., Air Cast walker). Sutures are removed at 2 to 3 weeks depending on the status of the wound.

\section{DISCUSSION AND REVIEW OF LITERATURE}

Classification and management of posterior malleolus fractures have been a controversial subject for a long time. Early 


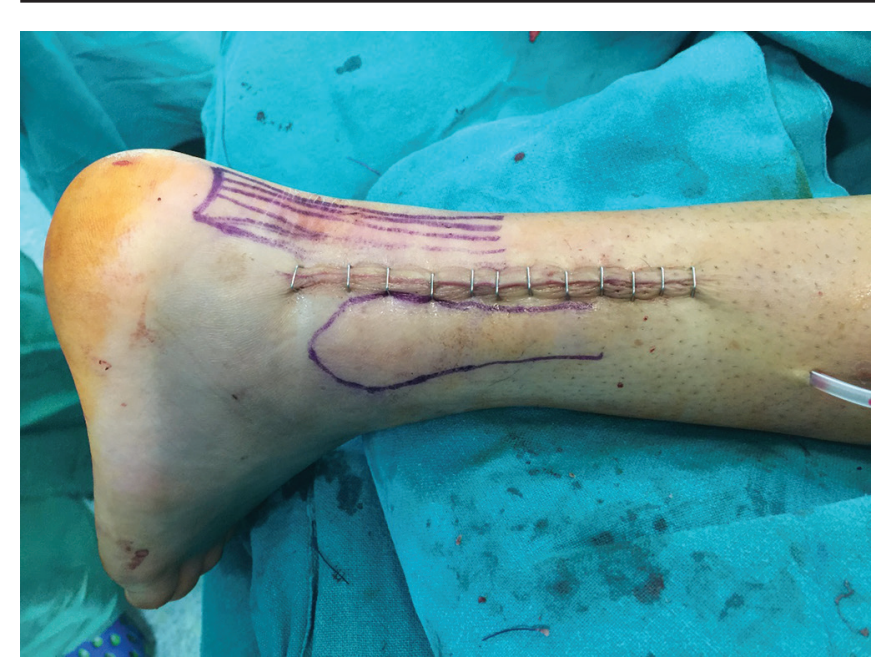

Fig. 10: Final clinical picture following wound closure of posterolateral approach

studies emphasized that most of the posterior malleolus fractures could be operated nonoperatively. Fractures involving 25 to $33 \%$ of articular surface on a lateral radiograph were considered for fixation. ${ }^{4-6}$ Over the years, articular congruity, stability of posterior syndesmosis, and fibular notch congruence have been given their due importance. Langenhuijsen et $\mathrm{al}^{13}$ emphasized that articular continuity was of utmost importance and recommended fixation for fractures involving more than $10 \%$ of articular surface. Jaskulka et $\mathrm{al}^{14}$ showed that those treated surgically performed better if more than $5 \%$ of articular surface was involved. Recent works have highlighted the role of posterior malleolus fixation in maintaining syndesmotic and rotational stability and shown to be at least as good as screw fixation. ${ }^{7,8}$

Multiple studies have now shown the inadequacy of lateral radiographs to adequately measure the size of the fragment. ${ }^{15,16}$ The first CT-based classification was given by Haraguchi et $\mathrm{al}^{17}$ who classified posterior malleolus fractures into three types, type I: posterolateral fragment (67\%), type II: medial extension fracture (19\%), type III: shell fractures (14\%) based on axial cuts on twodimensional CT scans. Bartoníček et $\mathrm{al}^{12}$ classified these fracture into five types. Type I: extra incisural fragment (intact fibular notch); type II: posterolateral fragment with fibular notch extension; type III: posteromedial two-part fracture with medial malleolus involvement; type IV: large posterolateral triangular fragment; type V: osteoporotic irregular fractures. The authors emphasized on the need of fixation for all fractures except type I, which can be managed conservatively. This observation from the authors where they advise most fractures to be managed operatively is in stark contrast to the line of thought that most fractures should be managed conservatively. It is also worth noting here that only extraincisural fractures which have no bearing on the syndesmotic stability and articular surface of ankle have been sug- gested to be amendable to conservative management.

Various approaches and methods for fixation of posterior malleolus have been described in literature. Old school and classical teaching has been to fix these fractures with indirect reduction and anterior to posterior (A to P) screws. ${ }^{5,6,18}$ This may be because previously the indications for fixation of these fractures were if the fracture involved more than 25 to $33 \%$ of articular surface. ${ }^{4-6}$ This provided a favorable environment for fixation of these fractures through A to P screw. We do not prefer this approach because (1) adequate reduction may not be always possible; (2) compression at fracture site may be difficult to achieve as a larger fragment is being fixed against a smaller fragment. Hence, it makes for a less stable construct; (3) fragments smaller than $15 \mathrm{~mm}$ are difficult to fix as all threads of partially threaded cancellous screw will not cross the fracture site and smaller threads do not provide adequate compression;, ${ }^{19}$ (4) multifragmentary and comminuted fractures cannot be fixed by this approach. As the indications of surgery have become broader over the years, this approach has taken a backseat in popularity with most surgeons.

Another approach for fixation of these fractures is lateral transmalleolar approach. This can only be used in fractures which are Weber type B with fracture line starting near tibial plafond where articular reduction of fibular notch can be looked at by displacing the fracture line. The factures are ultimately fixed with A to P screws but under direct vision. Kim et $\mathrm{al}^{20}$ in their study of 36 patients reported good results with this approach with no nonunion, no cases of infection, and similar range of motion compared with the other side. The only advantage this approach provides over indirect reduction with $\mathrm{A}$ to $\mathrm{P}$ screws is that adequate reduction can be achieved under direct vision. However, this approach cannot be used for multifragmentary and Weber type $\mathrm{C}$ fractures. ${ }^{19}$

Posterolateral approach is one of the most viable and widely used options for fixation of posterior malleolus fractures. This approach provides easy access to the fracture site with adequate exposure. ${ }^{9} \mathrm{O}^{\prime}$ Connor et $\mathrm{al}^{21}$ in their study found that patients treated with posterolateral plating by posterolateral approach had better clinical outcomes compared with those treated with indirect reduction with A to P screws. Verhage et $\mathrm{al}^{9}$ in their study used posterolateral approach for fixation of posterior malleolus and good articular reduction was achieved in all cases; $82 \%$ of their cases had a stable syndesmosis after posterior malleolus fixation. Batroníček et $\mathrm{al}^{19}$ suggested that Bartoníček and Rammelt type II to IV could easily be addressed by the posterolateral approach. Bartoníček and Rammelt type III fractures may require an additional posteromedial incision, but in most cases posterolateral approach is adequate. Li et $\mathrm{al}^{22}$ in their study on supination external rotation 
injury type IV showed that fixation of sizable posterior malleolus fragments by posterolateral approach provides much better syndesmotic stability compared with A to P screw fixation. Ruokun et $\mathrm{al}^{23}$ had excellent outcomes in 93\% patients using posterolateral approach. Only 3.1\% patients developed symptomatic posttraumatic arthritis. Both lag screws and buttress plates can be used for fixation of posterior malleolus fractures. Erdem et $\mathrm{al}^{24}$ showed good and equivalent results using both lag screws and buttress plates for fixation of posterior malleolus fractures by posterolateral approach and concluded that posterolateral approach is very safe with very few complications. Choi et $\mathrm{a}^{25}$ in their study on 50 patients noted local wound complications and sural nerve injury to be $4 \%$ each. Little et $\mathrm{al}^{26}$ in their study on 112 patients noted minor wound complications in $9.8 \%$, major wound complications in $2.7 \%$ of patients of supination external rotation injury treated with posterolateral approach.

In conclusion, posterolateral approach has evolved to be the gold standard approach in the fixation of posterior malleolar fragment, and each orthopedic surgeon should be well versed with it as they normally deal with ankle fractures.

\section{REFERENCES}

1. Court-Brown CM, McBirnie J, Wilson G. Adult ankle fractures-an increasing problem? Acta Orthop Scand 1998 Feb;69(1):43-47.

2. Koval KJ, Lurie J, Zhou W, Sparks MB, Cantu RV, Sporer $\mathrm{SM}$, Weinstein J. Ankle fractures in the elderly: what you get depends on where you live and who you see. J Orthop Trauma 2005 Oct;19(9):635-639.

3. Tejwani NC, Pahk B, Egol KA. Effect of posterior malleolus fracture on outcome after unstable ankle fracture. J Trauma 2010 Sep;69(3):666-669.

4. Nelson MC, Jensen NK. The treatment of trimalleolar fractures of the ankle. Surg Gynecol Obstet 1940;71:509-514.

5. Weber, BG. Die Verletzungen des oberen Sprunggelenkes. Bern (Switzerland): Huber; 1966.

6. Müller, ME.; Allgöwer, M.; Schneider, R.; Willenegger, H.; Perren, SM.; editors. Manual der Osteosynthese. 3. Aufl. Berlin: Springer; 1991. p. 595-612.

7. Gardner MJ, Brodsky A, Briggs SM, Nielson JH, Lorich DG. Fixation of posterior malleolar fracture provides greater syndesmotic stability. Clin Orthop Relat Res 2006 Jun;447: 165-171.

8. Miller AN, Carroll EA, Parker RJ, Helfet DL, Lorich DG. Posterior malleolar stabilization of syndesmotic injuries is equivalent to screw fixation. Clin Orthop Relat Res 2010 Apr;468(4):1129-1135.

9. Verhage SM, Boot F, Schipper IB, Hoogendoorn JM. Open reduction and internal fixation of posterior malleolar fractures using the posterolateral approach. Bone Joint J 2016 Jun;98(6):812-817.

10. von Rüden C, Hackl S, Woltmann A, Friederichs J, Bühren V, Hierholzer $C$. The postero-lateral approach-an alternative to closed anterior-posterior screw fixation of a dislocated postero-lateral fragment of the distal tibia in complex ankle fractures. Z Orthop Unfall 2015 Jun;153(3):289-295.

11. Lauge-Hansen N. Fractures of the ankle. II. Combined experimental-surgical and experimental-roentgenologic investigations. Arch Surg 1950 May;60(5):957-985.

12. Bartoníček J, Rammelt $S$, Kostlivý $K$, Vaněček V, Klika D, Trešl I. Anatomy and classification of the posterior tibial fragment in ankle fractures. Arch Orthop Trauma Surg 2015 Apr;135(4):506-516.

13. Langenhuijsen JF, Heetveld MJ, Ultee JM, Steller EP, Butzelaar RM. Results of ankle fractures with involvement of the posterior tibial margin. J Trauma 2002 Jul;53(1):55-60.

14. Jaskulka RA, Ittner G, Schedl R. Fractures of the posterior tibial margin: their role in the prognosis of malleolar fractures. J Trauma 1989 Nov;29(11):1565-1570.

15. Ferries JS, DeCoster TA, Firoozbakhsh KK, Garcia JF, Miller RA. Plain radiographic interpretation in trimalleolar ankle fractures poorly assesses posterior fragment size. J Orthop Trauma 1994 Aug;8(4):328-331.

16. Buchler L, Tannast M, Bonel HM, Weber M. Reliability of radiologic assessment of the fracture anatomy at the posterior tibial plafond in malleolar fractures. J Orthop Trauma 2009 Mar;23(3):208-212.

17. Haraguchi N, Haruyama H, Toga H, Kato F. Pathoanatomy of posterior malleolar fractures of the ankle. J Bone Joint Surg 2006 May;88(5):1085-1092.

18. Heim UF. Trimalleoar fractures: late results after fixation of the posterior fragment. Orthopedics 1989 Aug;12(8): 1053-1059.

19. Bartoníček J, Rammelt S, Tuček M. Posterior malleolar fractures: changing concepts and recent developments. Foot Ankle Clin 2017 Mar;22(1):125-145.

20. Kim MB, Lee YH, Kim JH, Lee JE, Baek GH. Lateral transmalleolar approach and miniscrews fixation for displaced posterolateral fragments of posterior malleolus fractures in adults: a consecutive study. J Orthop Trauma 2015 Feb;29(2): 105-109.

21. O'Connor TJ, Mueller B, Ly TV, Jacobson AR, Nelson ER, Cole PA. "A to $\mathrm{p}$ " screw versus posterolateral plate for posterior malleolus fixation in trimalleolar ankle fractures. J Orthop Trauma 2015 Apr;29(4):e151-e156.

22. Li M, Collier RC, Hill BW, Slinkard N, Ly TV. Comparing different surgical techniques for addressing the posterior malleolus in supination external rotation ankle fractures and the need for syndesmotic screw fixation. J Foot Ankle Surg 2017 Jul-Aug;56(4):730-734.

23. Ruokun H, Ming X, Zhihong X, Zhenhua F, Jingjing Z, Kai X, Jing L. Postoperative radiographic and clinical assessment of the treatment of posterior tibial plafond fractures using a posterior lateral incisional approach. J Foot Ankle Surg 2014 Nov-Dec;53(6):678-682

24. Erdem MN, Erken HY, Burc H, Saka G, Korkmaz MF, Aydogan M. Comparison of lag screw versus buttress plate fixation of posterior malleolar fractures. Foot Ankle Int 2014 Oct;35(10):1022-1030.

25. Choi JY, Kim JH, Ko HT, Suh JS. Single oblique posterolateral approach for open reduction and internal fixation of posterior malleolar fractures with an associated lateral malleolar fracture. J Foot Ankle Surg 2015 Jul-Aug;54(4):559-564.

26. Little MT, Berkes MB, Lazaro LE, Sculco PK, Helfet DL, Lorich DG. Complications following treatment of supination external rotation ankle fractures through the posterolateral approach. Foot Ankle Int 2013 Apr;34(4):523-529. 